Article

\title{
Excellent Carbonation Behavior of Rankinite Prepared by Calcining the C-S-H: Potential Recycling of Waste Concrete Powders for Prefabricated Building Products
}

\author{
Kai Wang *, Liang Ren and Luqing Yang \\ School of Civil and Architecture Engineering, East China Jiaotong University, Nanchang, 330013, China; \\ renliang@163.com (L.R.); 2017018085213020@ecjtu.jx.cn (L.Y.) \\ * Correspondence: 1506@ecjtu.jx.cn; Tel.: +86-791-8704-6084
}

Received: 23 July 2018; Accepted: 16 August 2018; Published: 19 August 2018

\begin{abstract}
Pure rankinite $\left(\mathrm{C}_{3} \mathrm{~S}_{2}\right)$ was prepared by calcining a C-S-H gel precursor at a temperature of $1300{ }^{\circ} \mathrm{C}$. The carbonation hardening behavior of the resulting rankinite was revealed by $\mathrm{X}$-ray diffraction (XRD), Fourier transform-infrared (FT-IR) spectroscopy, thermogravimetry and differential thermal analysis (TG/DTA), and scanning electron microscope (SEM) coupled with energy dispersive spectrum (EDS). The results indicate that the pure rankinite can be easily prepared at a lower temperature. The cubic compressive strengths of the resulting rankinite samples reach a value of $62.5 \mathrm{MPa}$ after $24 \mathrm{~h}$ of carbonation curing. The main carbonation products formed during the carbonation process are crystalline calcite, vaterite and highly polymerized amorphous silica gels. The formed carbonation products fill the pores and bind to each other, creating a dense microstructure, which contributes to the excellent mechanical strength. These results provide a novel insight into potential recycling of waste concrete powders for prefabricated building products with lower $\mathrm{CO}_{2}$ emissions.
\end{abstract}

Keywords: rankinite; carbonation; waste concrete; $\mathrm{CO}_{2}$

\section{Introduction}

At present, China is at the peak of infrastructure construction. The number of new concrete buildings being constructed and old buildings being demolished is enormous. It has been conservatively estimated that China produces nearly 100 million tons of waste concrete each year [1]. Disposal of waste concrete not only requires a large amount of land resources, but also poses serious environmental issues. In this age of greater environmental awareness, an increased number of environmental laws and the desire reduce construction costs, the recycling of waste concrete into recycled aggregate concrete has many benefits, thus, making it an attractive option [2-7]. In this way, waste concrete is crushed and the aggregate is separated and recovered. However, the crushing process also produces $25-40 \%$ waste concrete powder (WCP). These powders are mainly C-S-H gels, with large specific surface areas, high water demands and have not been well reused in the past [8-11].

On the other hand, the use of some low-lime calcium silicate phases such as dicalcium silicate $\left(\mathrm{C}_{2} \mathrm{~S}\right)$, rankinite $\left(\mathrm{C}_{3} \mathrm{~S}_{2}\right)$ and wollastonite (CS) to produce prefabricated buildings by carbonation, with significantly lower carbon dioxide emissions, is creating concern worldwide [12-16]. Rankinite $\left(\mathrm{C}_{3} \mathrm{~S}_{2}\right)$ is a low-lime calcium silicate phase. However, the traditional preparation method requires a higher calcination temperature $\left(1460{ }^{\circ} \mathrm{C}\right)$ and cannot be synthesized easily [17].

In this paper, pure $\mathrm{C}_{3} \mathrm{~S}_{2}$ minerals were prepared by calcining the prepared C-S-H gel precursor. The carbonation hardening behavior of the prepared $\mathrm{C}_{3} \mathrm{~S}_{2}$ was revealed by $\mathrm{X}$-ray diffraction (XRD), 
Fourier transform-infrared (FT-IR) spectroscopy, thermogravimetry and differential thermal analysis (TG/DTA), and scanning electron microscope (SEM) coupled with energy dispersive spectrum (EDS). The results provide a novel insight into the potential recycling of waste concrete powders for prefabricated building products, with lower $\mathrm{CO}_{2}$ emissions.

\section{Materials and Methods}

\subsection{Preparation of $C_{3} S_{2}$}

The C-S-H gel precursor was firstly prepared by exposing the mixtures of $\mathrm{CaO}$ and amorphous $\mathrm{SiO}_{2}$ (at 3:2 molar ratios) to a hydrothermal process. The water to solid ratio was 10 and the mixtures were sealed at $60^{\circ} \mathrm{C}$ for $6 \mathrm{~h}$ to allow the complete reaction at ambient pressure. Then, the prepared $\mathrm{C}-\mathrm{S}-\mathrm{H}$ gel precursor was dried in a vacuum oven at $100{ }^{\circ} \mathrm{C}$ for $24 \mathrm{~h}$. The dried C-S-H gel precursor was later calcined at $1300{ }^{\circ} \mathrm{C}$ for $2 \mathrm{~h}$. Subsequently, the prepared $\mathrm{C}_{3} \mathrm{~S}_{2}$ was cooled down to room temperature at a rapid cooling rate (approximately $500{ }^{\circ} \mathrm{C} / \mathrm{min}$ ) and ground for $20 \mathrm{~min}$ to achieve a Blaine fineness of $3970 \mathrm{~cm}^{2} / \mathrm{g}$.

\subsection{Carbonation of $C_{3} S_{2}$}

$\mathrm{C}_{3} \mathrm{~S}_{2}$ is a non-hydraulic mineral that does not set and harden when mixed with water. Thus, the resulting $C_{3} S_{2}$ powder was mixed with water at a water to solid ratio of 0.1 which is conducive to the carbonation reaction. Then, the wet mixtures were cast into a stainless steel mold $(20 \mathrm{~mm} \times 20 \mathrm{~mm}$ $\times 20 \mathrm{~mm}$ ) and compacted at $5 \mathrm{MPa}$ for $1 \mathrm{~min}$. Thereafter, the compacted $\mathrm{C}_{3} \mathrm{~S}_{2}$ samples were placed in a sealed stainless chamber at a temperature of $25 \pm 2{ }^{\circ} \mathrm{C}$, relative humidity of $70 \%, \mathrm{CO}_{2}$ concentration of $99.9 \%$ and $\mathrm{CO}_{2}$ pressure of $0.3 \mathrm{MPa}$ for $2,5,8$ and $24 \mathrm{~h}$, respectively.

\subsection{Test Methods}

\subsubsection{The Cubic Compressive Strength}

The cubic compressive strength was measured using a universal testing machine with a deformation speed of $0.5 \mathrm{~mm} / \mathrm{min}$. Six cubic samples with a dimension of $20 \mathrm{~mm} \times 20 \mathrm{~mm} \times 20 \mathrm{~mm}$ were tested.

\subsubsection{X-ray Diffraction Analysis}

The phase structure of the $\mathrm{C}_{3} \mathrm{~S}_{2}$ phase before and after carbonation were characterized by powder X-ray diffraction on a Rigaku SmartLab X-ray diffractometer (Rigaku Corporation, Tokyo Akishima, Japan) with $\mathrm{Cu} \mathrm{K} \mathrm{K}_{\alpha}$ radiation $(\lambda=1.5406 \AA)$. The X-ray tube was operated at $40 \mathrm{kV}$ and $15 \mathrm{~mA}$. The XRD patterns were recorded in the range of $10-55^{\circ}$.

\subsubsection{Fourier Transform-Infrared Spectroscopy}

The FT-IR spectroscopy data of the $\mathrm{C}_{3} \mathrm{~S}_{2}$ phase before and after carbonation was collected using a Bruker V70 Fourier transform infrared spectrometer (Bruker Corporation, Karlsruhe, Germany) with the $\mathrm{KBr}$ pellet technique, and the ranges of spectrograms were $1800-800 \mathrm{~cm}^{-1}$ at a resolution of $4 \mathrm{~cm}^{-1}$. Each spectrum presented in this paper is an average of six scans.

\subsubsection{Thermogravimetry and Differential Thermal Analysis}

The TG/DTA tests were performed using a simultaneous thermal analyzer (BJ-HCT-3, Nanjing sangli electronic equipment factory, Nanjing, China). The sample weighing $20 \mathrm{mg}$ was placed into a ceramic crucible, and then heated with a rate of $10{ }^{\circ} \mathrm{C} / \mathrm{min}$ from $20^{\circ} \mathrm{C}$ to $950{ }^{\circ} \mathrm{C}$ using an alumina reference material. $\mathrm{N}_{2}$ was used as purge gas during the TG/DTA tests. 


\subsubsection{Scanning Electron Microscope}

A small cut portion of the compacted $\mathrm{C}_{3} \mathrm{~S}_{2}$ sample before and after carbonation was dried and epoxy impregnated, respectively. After impregnation, one of the surfaces was polished to a 0.5 micrometer finish. The polished surface was sputter coated with a thin layer of gold ( $\mathrm{Au})$ and examined under a SEM in backscattered mode. A Merlin Compact ultra-high-resolution field emission scanning electron microscope (FEI Corporation, Hillsboro, OR, USA) coupled with Oxford energy dispersive spectrum at $20 \mathrm{kV}$ was used to acquire the images.

\section{Results}

\subsection{The Cubic Compressive Strength}

The cubic compressive strengths of the compacted $\mathrm{C}_{3} \mathrm{~S}_{2}$ samples carbonated for $0,2,5,8$ and $24 \mathrm{~h}$, respectively, are provided in Figure 1. The results show that compacted $C_{3} S_{2}$ samples can be rapidly hardened under carbonation conditions and reach a compressive strength of $62.5 \mathrm{MPa}$ within $24 \mathrm{~h}$. In addition, the strength development was mainly focused in the initial eight hours. These results indicate that $\mathrm{C}_{3} \mathrm{~S}_{2}$ prepared from C-S-H gel precursors can achieve excellent strength after rapid carbonation curing, providing a novel insight into potential recycling of waste concrete powders for prefabricated building products with lower $\mathrm{CO}_{2}$ emissions.

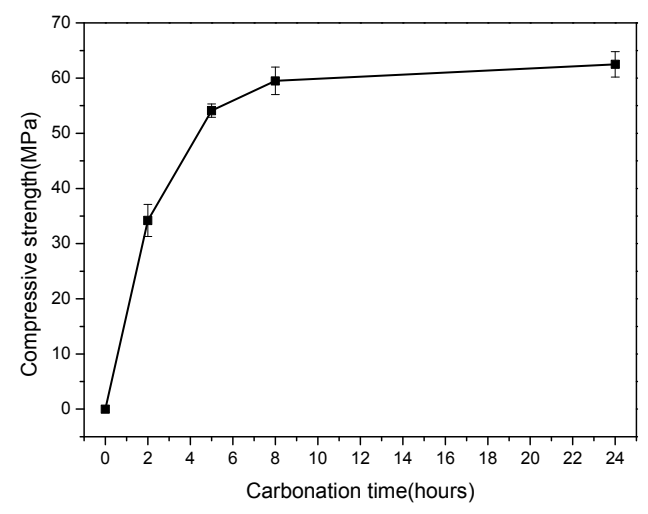

Figure 1. The compressive strength of compacted $C_{3} S_{2}$ samples with different carbonation times.

\subsection{Carbonation Products}

\subsubsection{XRD Analysis}

Figure 2 illustrates the XRD patterns of the $\mathrm{C}_{3} \mathrm{~S}_{2}$ phase before carbonation and carbonated for $24 \mathrm{~h}$. For the $\mathrm{C}_{3} \mathrm{~S}_{2}$ phase before carbonation, the pattern matches well with the published XRD pattern for $\mathrm{C}_{3} \mathrm{~S}_{2}[17,18]$. It is indicated that the pure $\mathrm{C}_{3} \mathrm{~S}_{2}$ phase can be easily prepared by calcining the C-S-H gel precursor at $1300{ }^{\circ} \mathrm{C}$ for two hours. After carbonation, the main crystalline carbonation products are calcite and vaterite and there are no diffraction peaks of silica, revealing that the silica formed during the carbonation is amorphous $\left(\mathrm{SiO}_{2}\right.$ gels). These results are distinct from the results achieved by Qian [17] who believes that crystalline quartz and cristobalite are the main silica products formed after $24 \mathrm{~h}$ of carbonation. Moreover, some unreacted $\mathrm{C}_{3} \mathrm{~S}_{2}$ phase still exists. The mass fractions of calcite, vaterite and unreacted $C_{3} S_{2}$ measured from the XRD pattern of the $C_{3} S_{2}$ phase after carbonation for $24 \mathrm{~h}$ by the Rietveld method are $44.7,20.1$ and $35.2 \%$, respectively. 


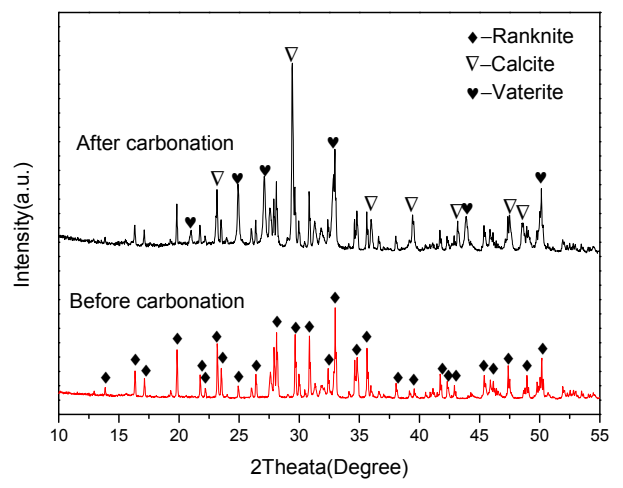

Figure 2. X-Ray Diffraction (XRD) patterns of the $\mathrm{C}_{3} \mathrm{~S}_{2}$ phase before carbonation and carbonated for $24 \mathrm{~h}$.

\subsubsection{FT-IR Analysis}

To reveal the structure of the $\mathrm{SiO}_{2}$ gels formed during carbonation, the FT-IR spectrums of the $\mathrm{C}_{3} \mathrm{~S}_{2}$ phase before carbonation and carbonated for $24 \mathrm{~h}$ are shown in Figure 3. It is well established that the FT-IR spectrum for silicate compounds exhibit a large absorption between 800 and $1200 \mathrm{~cm}^{-1}$, which correspond to the asymmetrical stretching vibration $\left(\mathrm{V}_{3}\right)$ of the Si-O bond. With the increasing polymerization degree of the silicate compound, the bonding strength of the $\mathrm{Si}-\mathrm{O}$ increases and the $\mathrm{V}_{3}$ band shifts to a higher wavenumber. For the $\mathrm{C}_{3} \mathrm{~S}_{2}$ phase before carbonation, there were three major absorptions bands located at approximately 847,945 and $998 \mathrm{~cm}^{-1}$. These are higher than the pure $\mathrm{C}_{2} \mathrm{~S}$ phase (orthosilicate group), indicating that the $\mathrm{C}_{3} \mathrm{~S}_{2}$ phase is composed of dimer silicate tetrahedrons (sorosilicates group), that is, one oxygen atom is shared between two neighboring tetrahedrals. For the $\mathrm{C}_{3} \mathrm{~S}_{2}$ phase after carbonation, new bands were observed to appear at approximately 867, 1440 and $1085 \mathrm{~cm}^{-1}$. The band located at around $1440 \mathrm{~cm}^{-1}$ is due to the asymmetric stretching $\left(\mathrm{V}_{3}\right)$ of the C-O bond present in $\mathrm{CaCO}_{3}$, and the band located at around $867 \mathrm{~cm}^{-1}$ corresponds to the out of plane bending vibration $\left(\mathrm{V}_{2}\right)$ of the same $\mathrm{C}-\mathrm{O}$ bond. Moreover, the position of the $\mathrm{V}_{3}$ vibration of $\mathrm{Si}-\mathrm{O}$ bonds were much higher $\left(1085 \mathrm{~cm}^{-1}\right)$ than the $V_{3}$ band position present in $C_{3} S_{2}$ phase before carbonation, indicating that highly polymerized $\mathrm{SiO}_{2}$ gels were formed after carbonation.

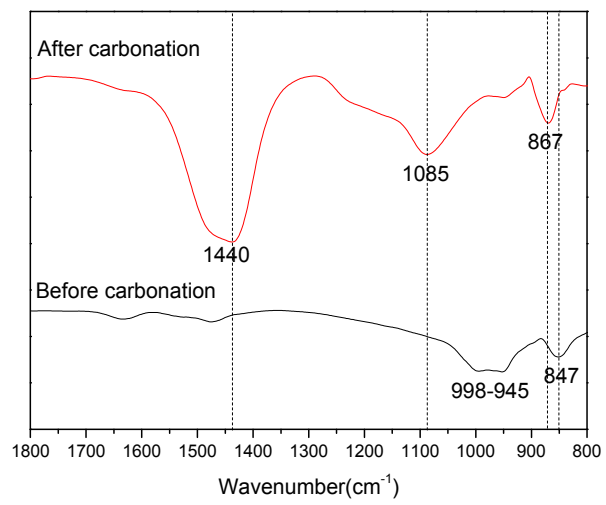

Figure 3. Fourier Transform-Infrared (FT-IR) spectrums of the $\mathrm{C}_{3} \mathrm{~S}_{2}$ phase before carbonation and carbonated for $24 \mathrm{~h}$.

\subsubsection{TG/DTA Analysis}

The TG/DTA curves for the $\mathrm{C}_{3} \mathrm{~S}_{2}$ phase carbonated for $24 \mathrm{~h}$ are presented in Figure 4 . The mass losses in the range of $20-400{ }^{\circ} \mathrm{C}$ were attributed to the dehydration of the gel water from the formed $\mathrm{SiO}_{2}$ gels. The mass losses in the range of $400-700{ }^{\circ} \mathrm{C}$ and $700-950{ }^{\circ} \mathrm{C}$ were used, respectively, 
to calculate the mass fraction of vaterite and calcite present in the carbonated $C_{3} S_{2}$ phase [19]. The mass losses from the decomposition of vaterite and calcite were 4.64 and $11.62 \%$, respectively, indicating that the $\mathrm{CaCO}_{3}$ of $\mathrm{C}_{3} \mathrm{~S}_{2}$ phase after carbonation was primarily formed from calcite and some vaterite. These results are consistent with the FT-IR and XRD results.

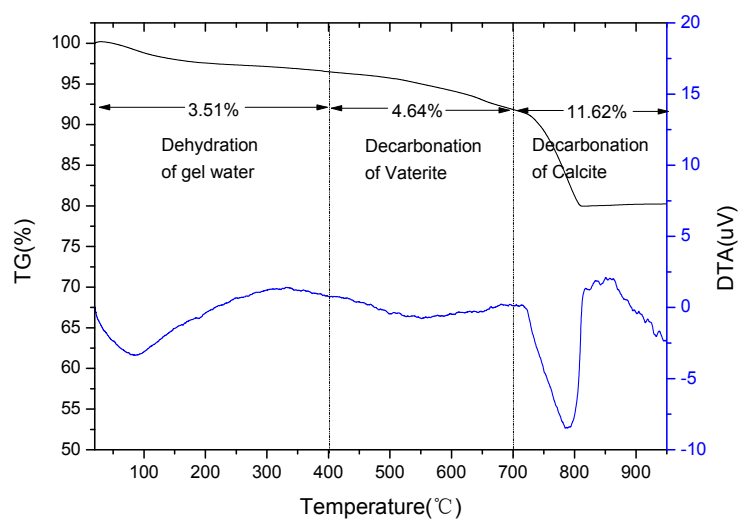

Figure 4. Thermogravimetry and Differential Thermal Analysis (TG/DTA) curves of the $C_{3} S_{2}$ phase carbonated for $24 \mathrm{~h}$.

\subsection{Microstructure}

Figures 5 and 6 show the SEM-EDS images of the compacted $\mathrm{C}_{3} \mathrm{~S}_{2}$ samples before and after carbonation, respectively. Before carbonation, the $\mathrm{C}_{3} \mathrm{~S}_{2}$ particles (approximately 5-25 $\mu \mathrm{m}$ ) were loosely packed. After carbonation, a dense microstructure was observed. According to the elemental maps and EDS results, the distribution of the carbonation products was illustrated as follows. The unreacted $\mathrm{C}_{3} \mathrm{~S}_{2}$ core was enveloped by a $\mathrm{SiO}_{2}$ gel rim and the initial pores of the sample were filled with $\mathrm{CaCO}_{3}$.
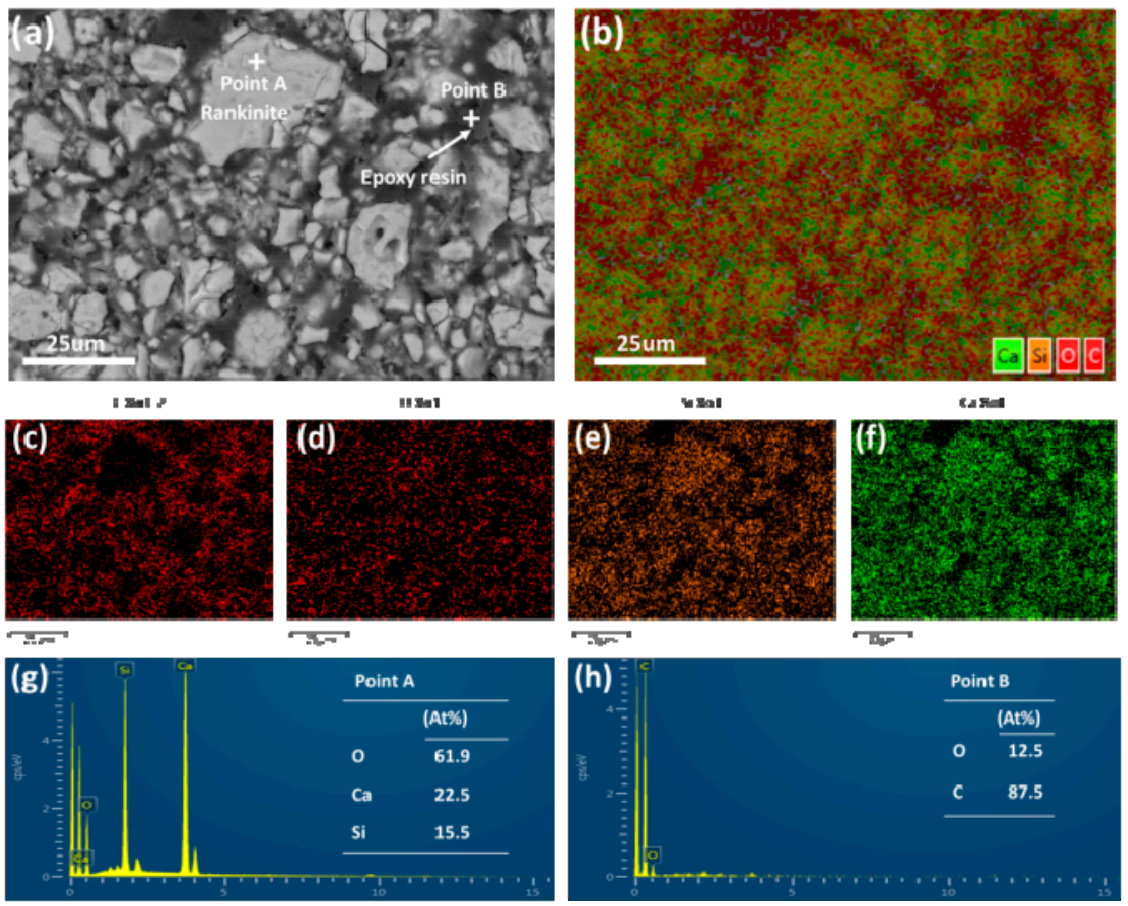

Figure 5. SEM and EDS images of the compacted $\mathrm{C}_{3} \mathrm{~S}_{2}$ samples before carbonation: (a) Backscattered Electron (BSE) image, (b-f) elemental maps for composite elements and C, O, Si, Ca, respectively, $(\mathbf{g}, \mathbf{h})$ EDS analysis of point A and B. 


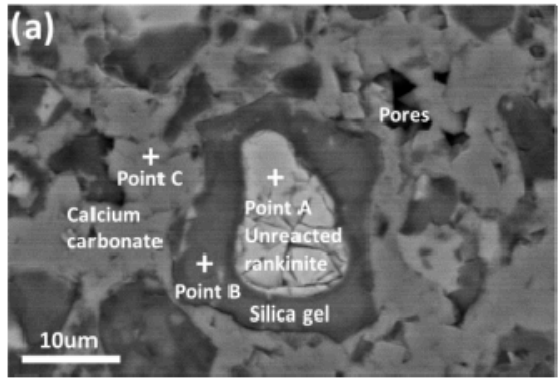

$\ln 2$

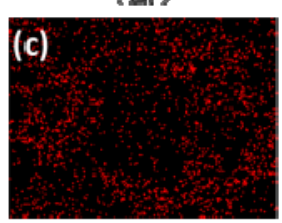

The

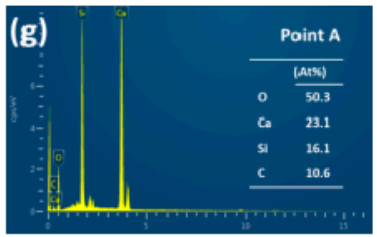

$\cos 1$
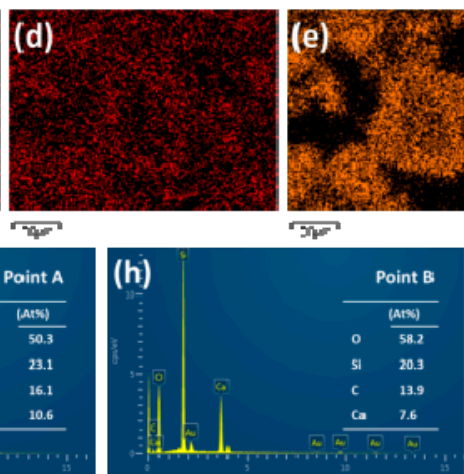

man
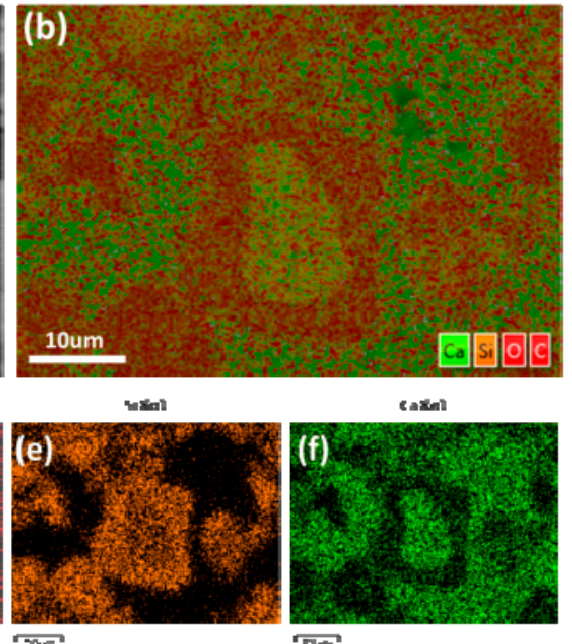

Tाm

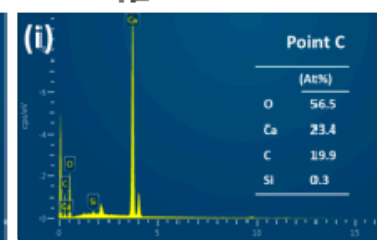

Figure 6. SEM and EDS images of the compacted $\mathrm{C}_{3} \mathrm{~S}_{2}$ samples carbonated for $24 \mathrm{~h}$ : (a) BSE image, (b-f) elemental maps for composite elements and C, O, Si, Ca, respectively, (g-i) EDS analysis of point $\mathrm{A}, \mathrm{B}$ and $\mathrm{C}$.

\subsection{Reaction Mechanism}

Based on the results achieved above, the reaction mechanism that occurred during the carbonation of $\mathrm{C}_{3} \mathrm{~S}_{2}$ can be illustrated in Figure 7. When the compacted $\mathrm{C}_{3} \mathrm{~S}_{2}$ samples that were partially filled with water come in contact with $\mathrm{CO}_{2}$, the $\mathrm{CO}_{2}$ will dissolve in the pore water and ionize to produce $\mathrm{H}^{+}$, $\mathrm{HCO}_{3}{ }^{-}$and $\mathrm{CO}_{3}{ }^{2-}$.

$$
\begin{aligned}
& \mathrm{CO}_{2}+\mathrm{H}_{2} \mathrm{O} \rightarrow \mathrm{H}_{2} \mathrm{CO}_{3} \\
& \mathrm{H}_{2} \mathrm{CO}_{3} \rightarrow \mathrm{H}^{+}+\mathrm{HCO}_{3}{ }^{-} \\
& \mathrm{HCO}_{3}{ }^{-} \rightarrow \mathrm{H}^{+}+\mathrm{CO}_{3}{ }^{2-}
\end{aligned}
$$

The ionization process of $\mathrm{H}_{2} \mathrm{CO}_{3}$ will generate a lot of $\mathrm{H}^{+}$, making the $\mathrm{pH}$ value of the pore water fall by approximately 3 units at $20^{\circ} \mathrm{C}$, typically from 7 to 4 . Compared with neutral water, the significantly increased $\mathrm{H}^{+}$concentration will induce the solvation of $\mathrm{Ca}^{2+}$ from the $\mathrm{C}_{3} \mathrm{~S}_{2}$ phase and drive the polymerization of the resulting silicon tetrahedral monomers $\left(\mathrm{H}_{4} \mathrm{SiO}_{4}\right)$ to form highly polymerized $\mathrm{SiO}_{2}$ gels.

$$
\begin{gathered}
6 \mathrm{H}^{+}+3 \mathrm{CaO} \cdot 2 \mathrm{SiO}_{2}+\mathrm{H}_{2} \mathrm{O} \rightarrow 3 \mathrm{Ca}^{2+}+2 \mathrm{H}_{4} \mathrm{SiO}_{4} \\
\mathrm{H}_{4} \mathrm{SiO}_{4} \rightarrow \mathrm{SiO}_{2}(\text { gel })+2 \mathrm{H}_{2} \mathrm{O}
\end{gathered}
$$

With the progress of dissolution and polymerization, the $\mathrm{H}^{+}$is gradually consumed and the $\mathrm{pH}$ of the pore solution is recovered, making it possible to precipitate calcium carbonate. At the beginning, vaterite and aragonite can be formed, but these $\mathrm{CaCO}_{3}$ polymorphs eventually revert to calcite. However, in some special circumstances, such as a suitable $\mathrm{pH}$ value or specific impurity ions for example, the metastable $\mathrm{CaCO}_{3}$ morphology can be stabilized [16]. However, the mechanism by which different polymorphs of $\mathrm{CaCO}_{3}$ form during the carbonation process is unclear. 


$$
\mathrm{Ca}^{2+}+\mathrm{CO}_{3}^{2-} \rightarrow \mathrm{CaCO}_{3}
$$

In general, the carbonation reaction of $\mathrm{C}_{3} \mathrm{~S}_{2}$ can be simplified by combining the above equations. It is important to note that there is no $\mathrm{H}_{2} \mathrm{O}$ in Equation (7). If the silicon tetrahedral monomers are completely polymerized, it is believed that the water plays only a catalytic role in the carbonation reaction process and is not consumed. These results are distinct from the results obtained by Ashraf [18] who believes that water will participate in the carbonation reaction to form C-S-H gels. A possible explanation is that the sample is not completely carbonated. If the C-S-H gels are carbonated completely, the chemically bound water in C-S-H will be released.

$$
3 \mathrm{CaO} \cdot 2 \mathrm{SiO}_{2}+3 \mathrm{CO}_{2} \rightarrow 3 \mathrm{CaCO}_{3}+2 \mathrm{SiO}_{2} \text { (gel) }
$$

As the carbonation reaction proceeds, the pores of the samples are gradually filled with crystalline $\mathrm{CaCO}_{3}$ and highly polymerized $\mathrm{SiO}_{2}$ gels and the reaction rate is greatly reduced, leaving the unreacted $\mathrm{C}_{3} \mathrm{~S}_{2}$ cores. Moreover, it is believed that $\mathrm{Ca}^{2+}$ is more mobile than silicon tetrahedral monomers during the carbonation process. Therefore, the highly polymerized $\mathrm{SiO}_{2}$ gels remain around the unreacted $\mathrm{C}_{3} \mathrm{~S}_{2}$ cores and the $\mathrm{CaCO}_{3}$ precipitates in the initial pores. Eventually, a dense microstructure will be formed, which contributes to the excellent mechanical strength.

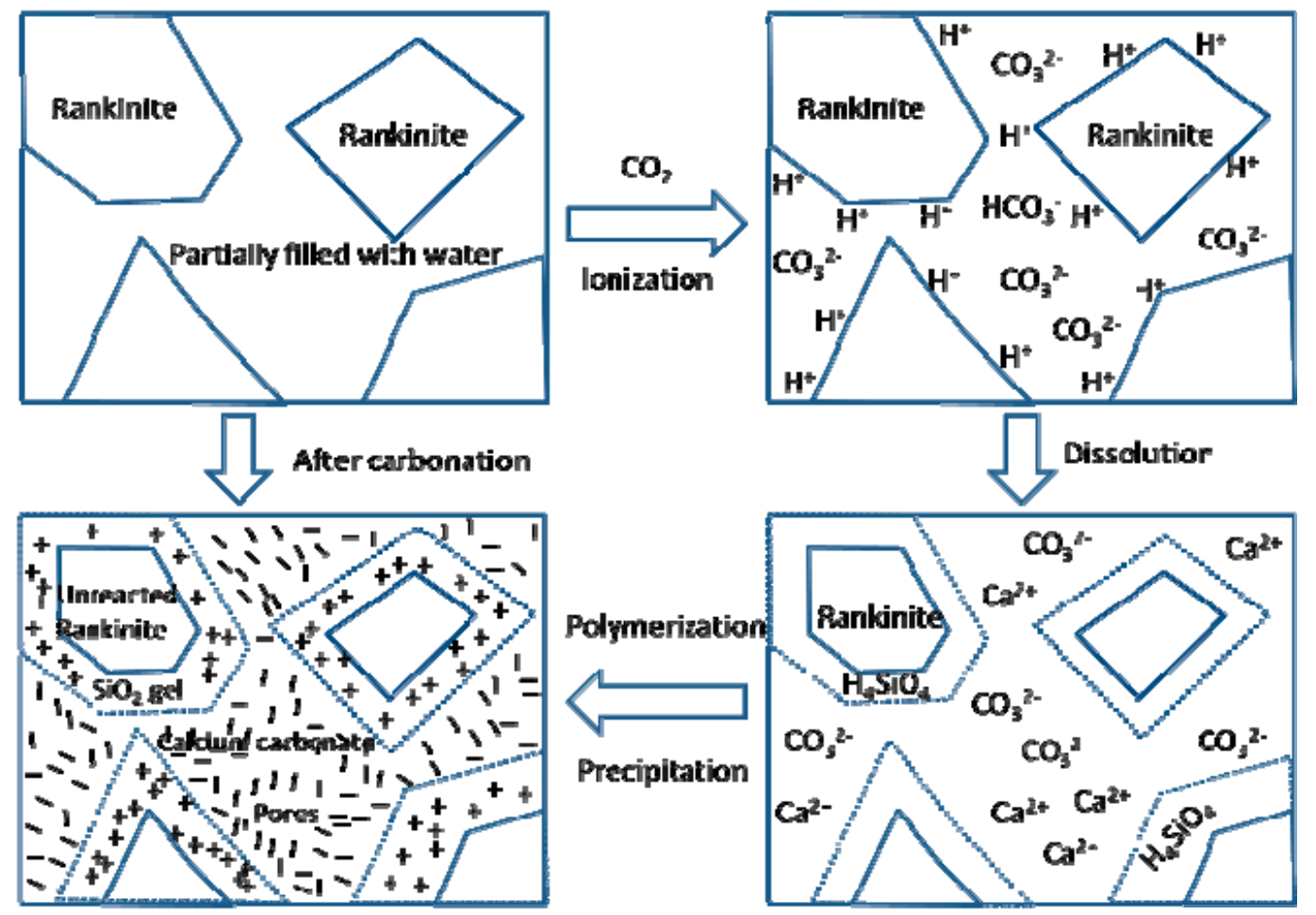

Figure 7. The reaction mechanism that occurred during the carbonation of $C_{3} S_{2}$.

\section{Conclusions}

Based on the aforementioned results and discussion, the primary conclusions drawn from this work are:

(1) The pure rankinite phase can be easily prepared by calcining the C-S-H gel precursor at a lower temperature.

(2) The cubic compressive strength of the resulting rankinite reaches a value of $62.5 \mathrm{MPa}$ after 24 $\mathrm{h}$ of carbonation curing. 
(3) The main carbonation products formed during the carbonation process are crystalline calcite, vaterite and highly polymerized amorphous silica gels.

(4) The formed carbonation products fill the pores and bind to each other, creating a dense microstructure which contributes to the excellent mechanical strength.

(5) The results provide a novel insight into potential recycling of waste concrete powders for prefabricated building products with lower $\mathrm{CO}_{2}$ emissions.

Author Contributions: K.W. conceived and designed the experiments; L.R. and L.Y. performed the experiments; K.W. analyzed the data and wrote the paper.

Funding: This research was funded by the National Natural Science Foundation of China (51478183), the Jiangxi Province Specialized Research Fund for Science and Technology Project of Higher Education, China (KJLD13039), and the Jiangxi Province Fund for Distinguished Young Scientists, China (20142BCB23012).

Acknowledgments: We would like to thank the funds from the National Natural Science Foundation of China (51478183), the Jiangxi Province Specialized Research Fund for Science and Technology Project of Higher Education, China (KJLD13039), and the Jiangxi Province Fund for Distinguished Young Scientists, China (20142BCB23012).

Conflicts of Interest: The authors declare no conflict of interest.

\section{References}

1. Li, X. Recycling and reuse of waste concrete in China. Resour. Conserv. Recy. 2008, 53, 36-44. [CrossRef]

2. Günçan, N.F. Using waste concrete as aggregate. Cement Concrete Res. 1995, 25, 1385-1390.

3. Silva, R.V.; de Brito, J.; Dhir, R.K. Properties and composition of recycled aggregates from construction and demolition waste suitable for concrete production. Constr. Build. Mater. 2014, 65, 201-217. [CrossRef]

4. Behera, M.; Bhattacharyya, S.K.; Minocha, A.K.; Deoliya, R.; Maiti, S. Recycled aggregate from C\&D waste \& its use in concrete -A breakthrough towards sustainability in construction sector: A review. Constr. Build. Mater. 2014, 68, 501-516.

5. Fan, C.C.; Huang, R.; Hwang, H.; Chao, S.J. Properties of concrete incorporating fine recycled aggregates from crushed concrete wastes. Constr. Build. Mater. 2016, 112, 708-715. [CrossRef]

6. Paris, J.M.; Roessler, J.G.; Ferraro, C.C.; Deford, H.D.; Townsend, T.G. A review of waste products utilized as supplements to Portland cement in concrete. J. Clean. Prod. 2016, 121, 1-18. [CrossRef]

7. Bru, K.; Touzé, S.; Bourgeois, F.; Lippiatt, N.; Ménard, Y. Assessment of a microwave-assisted recycling process for the recovery of high-quality aggregates from concrete waste. Int. J. Miner. Process. 2014, 126, 90-98. [CrossRef]

8. Ahmari, S.; Ren, X.; Toufigh, V.; Zhang, L. Production of geopolymeric binder from blended waste concrete powder and fly ash. Constr. Build. Mater. 2012, 35, 718-729. [CrossRef]

9. Kim, Y.J.; Choi, Y.W. Utilization of waste concrete powder as a substitution material for cement. Constr. Build. Mater. 2012, 30, 500-504. [CrossRef]

10. Moon, D.J.; Kim, Y.B.; Ryou, J.S. An approach for the recycling of waste concrete powder as cementitious materials. J. Ceram. Process. Res. 2008, 9, 278-281.

11. Ma, X.; Wang, Z. Effect of Ground Waste Concrete Powder on Cement Properties. Adv. Mater. Sci. Eng. 2013, 2013, 1-5. [CrossRef]

12. Ashraf, W.; Olek, J. Elucidating the accelerated carbonation products of calcium silicates using multi-technique approach. J. $\mathrm{CO}_{2}$ Util. 2018, 23, 61-74. [CrossRef]

13. Ashraf, W.; Olek, J.; Jain, J. Microscopic features of non-hydraulic calcium silicate cement paste and mortar. Cement Concrete Res. 2017, 100, 361-372. [CrossRef]

14. Ashraf, W. Carbonation of cement-based materials: Challenges and opportunities. Constr. Build. Mater. 2016, 120, 558-570. [CrossRef]

15. Chang, J.; Fang, Y.; Shang, X. The role of $\beta-C_{2} S$ and $\gamma-C_{2} S$ in carbon capture and strength development. Mater. Struct. 2016, 49, 4417-4424. [CrossRef]

16. Liu, S.; Dou, Z.; Zhang, S.; Zhang, H.; Guan, X. Effect of sodium hydroxide on the carbonation behavior of $\beta$-dicalcium silicate. Constr. Build. Mater. 2017, 150, 591-594. [CrossRef]

17. Qian, B.; Li, X.; Shen, X. Preparation and accelerated carbonation of low temperature sintered clinker with low Ca/Si ratio. J. Clean. Prod. 2016, 120, 249-259. [CrossRef] 
18. Ashraf, W.; Olek, J. Carbonation behavior of hydraulic and non-hydraulic calcium silicates: potential of utilizing low-lime calcium silicates in cement-based materials. J. Mater. Sci. 2016, 51, 6173-6191. [CrossRef]

19. Fang, Y.; Chang, J. Microstructure changes of waste hydrated cement paste induced by accelerated carbonation. Constr. Build. Mater. 2015, 76, 360-365. [CrossRef] 